\title{
Situación político-laboral en Venezuela: la estabilidad perdida ${ }^{1}$
}

\author{
Héctor Lucena \\ Universidad de Carabobo. Venezuela \\ hlucena@postgrado.uc.edu.ve
}

\section{Resumen}

En el presente artículo se analizan las agudas transformaciones políticas ocurridas en Venezuela en las últimas décadas, que han llevado a una notable inestabilidad institucional. Se analizan los factores que contribuyeron a la pérdida de la estabilidad alcanzada, destacando la falta de representatividad de las organizaciones políticas y sociales que tradicionalmente habían representado a grandes contingentes de seguidores. De estas organizaciones, el análisis se centra en el papel del movimiento sindical. Ascienden al poder político nuevos actores, que triunfaron electoralmente con abultados márgenes, en donde destaca una corriente militarista, en compañía de grupos de izquierda, y vinculada a los fallidos golpes de estado de principios de la década de los noventa. Esto plantea al movimiento sindical una drástica modificación de su situación, ya que de organización cuasi corporativa, ha pasado a ser uno de los ejes de la acción confrontativa con el régimen, el cual no ha cesado de promover el hostigamiento.

Palabras clave: sindicalismo, militarismo, partidos políticos, empresariado, Venezuela.

\section{Abstract}

Presently article the sharp political transformations are analyzed happened in Venezuela in the last decades that have taken to a remarkable institutional uncertainty. The factors are analyzed that contributed to the loss of the reached stability, highlighting the loss of representativeness of the political and social organizations that traditionally had represented to big contingents of followers. Of these organizations, the analysis is centered in the paper of the union movement. They ascend to the power political new actors that they triumphed electorally with swollen margins where an average militarist highlights, in company of left groups, and linked to the bankrupt coups of principles of the decade of the ninety. This outlines to the union movement a drastic modification of their situation, since of quasi corporate organization, to become one of the axes of the oppositional action against the régime, which has not ceased of promoting the harassment.

Key words: unions, militarism, political parties, managers, Venezuela.

1. Para el desarrollo de esta línea de trabajo, el autor ha contado con el apoyo del Consejo de Desarrollo Científico y Humanístico de la Universidad de Carabobo. 


\section{Sumario}

Problema a plantear Huelga petrolera

La consolidación democrática y el crecimiento económico facilitan el establecimiento de las relaciones laborales y del sindicalismo durante los años sesenta y setenta

Signos de agotamiento político y económico en los ochenta Tercera etapa: irrupción del militarismo en los años noventa

Cuarta etapa: nuevo bloque en el ejercicio del poder político. Composición y mutación Gobierno y movimiento sindical El referéndum sindical

Recuperación del movimiento sindical: el hostigamiento gubernamental

La oposición conquista la calle

Tensiones máximas

El movimiento sindical y el 11 de abril del 2002

CTV: ¿actor político o actor laboral?

La relación con el empresariado

¿En dónde estamos?

Bibliografía

Relaciones de trabajo: las primeras derrotas oficialistas. ¿Cuál ha sido el enfoque del gobierno de Hugo Chávez con los temas de las relaciones laborales?

\section{Problema a plantear}

Venezuela se ha convertido, en el inicio del siglo XXI, en el país más controversial en cuanto a su desenvolvimiento político en toda América Latina. Esto es más llamativo si se toma en cuenta que el país se caracterizó por su estabilidad política y laboral a lo largo de varias décadas, que al mismo tiempo fueron marcadas por una notable turbulencia en toda la región. Autoritarismo en los países suramericanos, guerrillas y guerras civiles en otros - países andinos y centroamericanos- . La inestabilidad política y laboral en Venezuela, sus orígenes y causas en los últimos veinte años, ¿qué factores contribuyeron a la creciente inestabilidad? Las llamadas de atención, ¿han significado una rectificación y un aprendizaje democrático? El movimiento de los trabajadores, ¿qué ha papel ha jugado en todo esto?

Es necesario considerar el factor agotamiento del sistema político en primer lugar, porque la sociedad venezolana viene viviendo una etapa en donde se ha incrementado la pugnacidad y la desconcertación política. El consenso en el cual descansaba el modelo sociopolítico y económico venezolano venía experimentando signos de agotamiento ya desde la década de 1980, como consecuencia de la errática manera de manejar los asuntos públicos, que fue desencantando y frustrando a una población que había depositado una alta dosis de confianza en los liderazgos partidistas y económicos durante más de tres décadas. El sistema político fue perdiendo capacidad para resolver los conflictos (Lucena, 1985: 12; Iturraspe, 2000; López, 2002).

El gobierno de Hugo Chávez, que asume el poder político en febrero de 1999, plantea una relación distinta con el movimiento sindical a la que venía 
funcionando durante casi cuatro décadas. La relación se caracteriza por la confrontación. La hostilidad hacia el movimiento sindical y las reacciones de éste son el eje del análisis en el presente documento. No se trata del único sector hacia donde se dirigen hostilidades, entre otros, también el sector empresarial, la Iglesia católica, los partidos de la oposición, son objeto de hostilidades, lo que, particularmente con los empresarios, da lugar a más encuentros que desencuentros entre éstos y los sindicatos, al tener como contrario común a las políticas gubernamentales. Se trata de una democracia que rompe con el pactismo que caracterizó el período precedente de más de cuarenta años ${ }^{2}$.

\section{La consolidación democrática y el crecimiento económico facilitan el establecimiento de las relaciones laborales y del sindicalismo durante los años sesenta y setenta}

En Venezuela se abraza el sistema democrático en 1958, luego de una década de militarismo — período de gobierno de M. Pérez Jiménez- que fue el desenlace de una incipiente experiencia democratizadora en la década de 1940. Los sectores civiles que accedieron al poder político en 1945 -Acción Democrática-, por vía de un golpe cívico militar, reconocieron posteriormente su sectarismo y entendieron el valor de los acuerdos con otros sectores políticos, sociales y económicos, lo que efectivamente ocurrió en la lucha contra la dictadura y el establecimiento del régimen democrático a partir de 1958. Tal fue el aprendizaje que experimentó el liderazgo del partido Acción Democrática, ya que por su sectarismo se abortó el incipiente proceso democratizador que se había iniciado gradualmente desde la mitad de los años treinta.

Coincidente con el inicio del proceso democratizador venezolano, en donde se realizaron elecciones presidenciales y legislativas en diciembre de 1958, que atrajo una entusiasta participación electoral de más del 92\% (Romero, 2001: 230), irrumpe en Cuba el triunfo de los revolucionarios al mando de Fidel Castro con el nacimiento del año nuevo de 1959. El desplome del gobierno dictatorial cubano de Fulgencio Batista, así como de su ejército, dio campo abierto al nuevo gobierno cubano para instaurar procesos políticos inéditos en la región.

Ante esta nueva realidad geopolítica, que colocó al nuevo gobierno cubano en el centro de tensiones de los superpoderes, el gobierno de los EEUU reorienta su actividad diplomática en la región y, como consecuencia de ello, se proponen programas de fomento y desarrollo de las democracias, desta-

2. Las democracias de los años ochenta para acá, reestablecidas posteriormente al cierre del ciclo autoritario, señala Livesley Geraldine («Democracy in Latin america: Mobilization, power and the serch for rew politics», Manchester University Press, 1999), condujeron a la desmovilización de los movimientos que emergieron en la lucha por la democracia y su posterior marginalización del poder. Aunque no coincide con el ciclo venezolano, ya que su democracia es de refundación de 1958 para acá, sí se advierte en el discurso del nuevo liderazgo una condena al pactismo en el cual descansaba el sistema político. 
Cuadro 1. Porcentajes de abstención electoral.

\begin{tabular}{rr}
\hline 1963 & $9,22 \%$ \\
1968 & $5,64 \%$ \\
1973 & $3,48 \%$ \\
1978 & $12,44 \%$ \\
1983 & $12,25 \%$ \\
\hline
\end{tabular}

cándose la Alianza para el Progreso ${ }^{3}$ y los Cuerpos de Paz. En este marco, Venezuela fue percibida por la potencia del norte como un modelo democrático a fortalecer en el continente. Si bien Venezuela no fue inmune al efecto demostración de la revolución cubana, ya que en 1962 brotó un movimiento guerrillero en la región occidental del país, que luego irradió también a otras regiones, pero que cinco años más tarde fue un movimiento prácticamente derrotado, lo que llevó exitosamente al gobierno - R. Caldera- a promover una política de pacificación en 1968-1969 que terminó por minimizar esta experiencia guerrillera e integrar a la mayoría de los grupos radicales al establecimiento político (Valsalice, 1979). Las décadas de 1960, 1970 y primera mitad de 1980 contribuyeron a consolidar el sistema político venezolano, lo evidencian los porcentajes de abstención electoral, verdaderamente bajos (Romero, 2001: 230) (cuadro 1).

En la Universidad de California Los Ángeles _ UCLA — se inicio hace 55 años la encuesta Fitzgibbon, que elabora un ranking sobre la extensión y la efectividad de la democracia en veinte países latinoamericanos. A partir de 1965 Venezuela alcanzó un quinto lugar y en los años sucesivos llegó a estar ubicada sucesivamente en las cuatro encuestas desde 1975 hasta 1991 en el segundo lugar, sólo superada por Costa Rica. Fueron, obviamente, los años de la década de los cincuenta los de peor ubicación, sin embargo, la situación política reciente dio lugar a que en la última encuesta - 2000 - la percepción de los encuestados colocara al país en el séptimo lugar, lo que evidencia un retroceso ${ }^{4}$.

Al tiempo que ocurrían estos procesos de fortalecimiento democrático, en la mayoría de los países de Suramérica y Centroamérica ocurrían desplazamientos de los regímenes democráticos por parte de gobiernos autoritarios.

3. La Organización de Estados Americanos - OEA — convocó una asamblea en donde EEUU propuso este programa, cuya administración le fue asignada a Teodoro Moscoso. El programa tuvo corta duración, ya que años más tarde la política de EEUU hacia la región adoptó otros mecanismos.

4. Los encuestados son distinguidos profesores latinoamericanistas de los EEUU, y toman en cuenta quince criterios entre los cuales se encuentran aspectos educativos, niveles de vida, madurez política, libertad de prensa, de elecciones, sistemas de partidos, judicial, derechos civiles, gobiernos locales. En la encuesta del año 2000, participaron 103 latinoamericanistas (Kelly, 2002: 10-13). 
La fe democrática evidenciada en la alta participación electoral repercutió en la organización de instituciones sociales, aunque bajo el influjo y la orientación de las organizaciones partidistas beneficiarias del ejercicio del poder político. La estabilidad de Venezuela en esta etapa permitió que se convirtiera en un centro de atracción de inmigración del resto del continente, e incluso europea.

El estado de las relaciones laborales y del desarrollo sindical en general para el momento del inicio del restablecimiento democrático era atrasado. Lo que no quiere decir que el papel del movimiento sindical en la lucha por la democracia fuera inexistente. La estructura económica estaba poco diversificada, petróleo, agricultura, comercio y servicios y empleo público eran los pilares en donde descansaba el empleo de la mayor parte de la población. La industria manufacturera alcanzó una dimensión importante apenas en la década de los sesenta. En América Latina, Venezuela era un país que se le identificaba sólo por su producción y exportación de petróleo crudo. Es por ello que los acuerdos que acompañan el restablecimiento de la democracia asignan especial atención a la modernización productiva, aprovechando el enorme ingreso que recibía el Estado de los impuestos y las regalías petroleras 5 . Esta modernización adopta decididamente el fomento de la industrialización por vía de la sustitución de las importaciones, así como reiterar el colocar en manos de la inversión del Estado el emprendimiento de megaproyectos de empresas básicas.

El eje central de la existencia de las relaciones de trabajo radica en el reconocimiento de las partes o los actores colectivos entre sí. La tradición confrontativa en las relaciones laborales en las décadas precedentes, en los pocos sectores que pudieron alcanzar un cierto grado de organización, como el caso del petrolero, encontraron un nuevo marco de consensualidad para asegurar las bases para el desarrollo sindical. El fomento de los sindicatos, la promoción y difusión de las negociaciones colectivas en las diversas regiones y ramas productivas, que florecieron al amparo del estímulo estatal, fue la manifestación en primer lugar de la estabilidad política, así como de la existencia de un sostenido ritmo de expansión económica, con efectos ciertos en el mejoramiento de la calidad de la vida. En los diez y siete años que van desde 1961 hasta 1977, el PIB creció a un promedio del 5,8\% anual (Lucena, Hernández y Goizueta, 1985). Evidentemente, para entonces, éste fue el ritmo más alto de crecimiento en toda la región. Del lado de los trabajadores se fue construyendo un patrimonio de conquistas e intereses, representado por las legislaciones e instituciones laborales, destacándose en ella la negociación colectiva, lo que alcanzó su clímax evolutivo en los años setenta ${ }^{6}$. La sindicalización llegó a alcanzar un

5. Regalías o royalty, así se identifica en la Legislación de Hidrocarburos el porcentaje de beneficios que recibe la nación como propietaria del subsuelo en donde reposan los yacimientos.

6. Se advierte que esta valoración en nada se acerca a juicios que dieron lugar a la categoría de «la aristocracia obrera» en el seno del movimiento de los trabajadores latinoamericanos, «alegaban que estos trabajadores representaban un grupo privilegiado en los mercados nacionales de trabajo. Sostenían que los trabajadores industriales... que competían por un reducido número de empleos generados, dentro de la industria manufacturera, por una expansión 
porcentaje del $30 \%$ y la cobertura de las negociaciones colectivas superaron ampliamente este porcentaje por el efecto erga omnes, que se extiende a toda la masa laboral de la empresa o del sector, si fuere el caso de negociaciones de este ámbito, los beneficios negociados, independientemente de su afiliación o no a un sindicato (Alfonso, 1967: 590 [T. II]).

Es importante destacar que, a lo largo de este período, siempre se mantuvo una dualidad entre los trabajadores de los sectores modernos y/o exportadores y otros segmentos del aparato productivo, que consistía en distintas condiciones de beneficios y accesos al bienestar. Por tanto, no llegó a consolidarse una sociedad del bienestar en el buen sentido del término, aunque los trabajadores de los sectores tradicionales eran beneficiarios de servicios provistos por el Estado que se caracterizaron en este período de calidad razonable. Ni tampoco llegaron a extenderse las instituciones de las relaciones laborales a todos los sectores productivos (Dombois y Pries, 2000), pero las áreas económicas en donde se implantaron estas instituciones, jugaron un papel influyente en el resto de la vida laboral del país. Por ejemplo, las negociaciones nacionales de las cúpulas sindicales y empresariales con el gobierno para definir anualmente el salario mínimo, al final éste era aplicado a todos los establecimientos con personal asalariado, lo que extendía a un universo más allá de la población sindicalizada los beneficios de este acuerdo.

\section{Signos de agotamiento político y económico en los ochenta}

Esta segunda etapa se caracteriza por mostrar los primeros signos de agotamiento del sistema económico, con repercusiones directas en el sistema político venezolano. En el primer quinquenio de los ochenta ocurre un decrecimiento del $1,7 \%$ del PIB, la remuneración real promedio descendió un $25 \%$, la tasa de desempleo abierto pasó del 5,6 al 10,3\% y la distribución del ingreso empeoró (Valecillos, 1989). En las dos décadas anteriores, los salarios reales habían subido y a partir de 1979 empezaron su caída sostenida. Los convenios colectivos no pudieron reponerla, es por ello que el movimiento sindical apelaba a presiones para alcanzar medidas ejecutivas o legislativas que compensaran el deterioro salarial, lo que permitió el alcance de una ley general de aumentos de sueldos y salarios que al menos recuperaba los salarios mínimos en 1980 . Sin embargo, en los años sucesivos esta conquista se diluyó por el incremento inflacionario (Lucena y Hernández, 1985; Mc Coy, 1988).

En febrero de 1982, se interrumpen más de veinte años de estabilidad cambiaria, iniciándose un proceso continuado de devaluaciones de la moneda nacional. A partir de esta etapa, salvo en 1997 que muestra un índice realmente positivo, el resto de los años se evidencia una situación recesiva, que lleva ya más de veinte años, en donde los niveles de vida se han venido dete-

muy lenta en capital intensivo, conformaban una aristocracia obrera, conservadora políticamente y conformista en lo social» (Bergquist, 1986: 26). La llamada construcción de un patrimonio institucional la desarrollamos mas detenidamente en Lucena (1999). 
Cuadro 2. Venezuela: Producto Interior Bruto.

\begin{tabular}{lr}
\hline Años & PIB \% \\
\hline $1983-1992$ & 3,72 \\
1993 & 0,28 \\
1994 & $-2,35$ \\
1995 & 3,95 \\
1996 & $-0,20$ \\
1997 & 6,37 \\
1998 & 0,17 \\
1999 & $-6,09$ \\
2000 & 3,24 \\
2001 & 2,67 \\
2002 & $-8,00$ \\
\hline
\end{tabular}

Fuente: Banco Central de Venezuela.

riorando, el PIB per cápita pasó de más de 6 mil dólares en la mitad de la década de 1970 a sólo 3 mil dólares a principios del nuevo siglo (cuadro 2).

Al funcionamiento del sistema político se le señala que él mismo se había congelado, había sido hipotecado por los partidos políticos beneficiarios del acceso al poder. En las elecciones de 1988, la abstención se remontó al 18\%. Acción Democrática y el partido socialcristiano —COPEI — habían copado casi todos los escenarios de participación popular, y habían sometido a prácticas clientelares y de amiguismo el reparto de las cuotas de poder. De hecho, esta práctica de intermediación del bipartidismo para casi todos los actos normales de la vida pública dio lugar a lo que llamamos la «despolitización», porque el ciudadano dejaba en manos del partido, a través de sus dirigentes, todos los asuntos que tenían que ver con la política. Estos partidos, ubicados el primero en el centro izquierda y el segundo en el centro político, tenían el mayor control de las organizaciones sociales incluyendo los sindicatos. Éstos estaban tutelados por los partidos, quienes determinaban los pasos que debían seguir los sindicatos ante los asuntos más relevantes y al mismo tiempo subordinados al Estado, ya que éste administraba la gran riqueza petrolera, que en definitiva tenía una enorme repercusión en las relaciones de trabajo.

En cuanto a la izquierda, entendiendo que la misma $\mathrm{AD}$ se autocalificaba así, a su vez existía un movimiento más radical, marxista y no marxista, que incluso venía operando legalmente desde el proceso de pacificación — 1969-1970_, pero su peso en las participaciones electorales no llegaba a superar el 10\%, y en el mundo sindical también formaba parte de la minoría.

En general, la tasa de afiliación a los sindicatos, que había crecido realmente en las décadas pasadas llegando a un 30\%, empezó a declinar, llegando a los niveles actuales - 2002- a un 14\% (CNE, 2002). En la década de 
1980 ocurre una transformación importante en el futuro del sindicalismo y de las relaciones laborales, en que los trabajadores amparados por la negociación del sector público superan a los del sector privado, hecho que se mantiene sostenidamente hasta nuestros días.

Hacia el final de esta década - 27 y 28 de febrero de 1989-, se presentó un levantamiento popular que desafió radicalmente el statu quo imperante, si bien no se trató de una acción dirigida por un determinado grupo político, ni tampoco hubo ninguno que se atreviera a reclamar el liderazgo del levantamiento cuando ocurrió o después de la explosión social. Fue efectivamente una acción demostrativa del descontento existente en las zonas más pobres de las grandes ciudades venezolanas, en donde los pobladores, empleados, desempleados y subempleados, tomaron las principales calles para llevar a cabo un intenso saqueo de comercios y lugares públicos, que luego de dos días de ausencia de gobierno fue sofocado cruentamente con acciones militares. El liderazgo político, institucional y económico, se comprometió en un mea culpa, reconociendo que el levantamiento de los pobladores de aquellas zonas pobres que desobedecieron las reglas de convivencia establecidas tenía fundamento en el hecho de que el sistema político y económico no venía dando respuesta adecuada a los problemas de pobreza y exclusión que día a día se incrementaban. Por tanto, luego de un inicial mea culpa, al poco tiempo parecía que no había pasado nada, y se ignoraron compromisos de reformas políticas y económicas enunciados nerviosamente en el momento del levantamiento popular.

Para el movimiento sindical este levantamiento significó una afrenta, ya que se evidenció su falta de tacto en captar el sentimiento popular de los sectores más pobres. Incluso en un esfuerzo a posteriori por mostrar su capacidad de convocatoria, la CTV llamó a un paro nacional de un día, el 18 de mayo de 1989, sin embargo, las contradicciones en su liderazgo disminuyeron el impacto de esta acción, ya que, mientras el presidente de la CTV invocaba como motivante del paro la lucha contra las políticas económicas del gobierno de orientación neoliberal, la Secretaría Sindical de AD, verdadero poder en el sector, colocaba en primer lugar la lucha contra los especuladores, brindando así una coartada al gobierno, pero distanciándose de los sectores más afectados por la situación económica.

De las muy contadas reformas que esta coyuntura permitió llevar a cabo, se encuentra el fomento del proceso de descentralización política que llevó a la elección directa de gobernadores y alcaldes. Hecho muy importante, porque la crisis de gobernabilidad observada en los años siguientes no generó en mayores consecuencias, porque estos mecanismos contribuyeron a reducir y a administrar las tensiones.

\section{Tercera etapa: irrupción del militarismo en los años noventa}

Es bajo esta atmósfera de malestar que dejan los acontecimientos de fines de los ochenta, que ocurren dos levantamientos militares en febrero y noviembre de 1992, que reflejan la profunda crisis política que vive el país. Es lla- 
mativo el contraste con el hecho de que en la región latinoamericana no existe esta tendencia militarista exitosa en esta época. Las banderas del combate a la corrupción, a la pobreza y a la exclusión son los motivadores de esos levantamientos, que evidencian la crisis del bipartidismo y del sindicalismo como movimiento social, ya que habían perdido la sintonía con sus representados. Si bien los alzamientos fueron derrotados militarmente, sí dejaron sentir importantes consecuencias políticas, porque fueron el germen que en lo inmediato aceleró el descontento existente con el ejercicio presidencial, que se manifestó en un juicio promovido por la Fiscalía General, que llevó a la Corte Suprema de Justicia a decidir la destitución del presidente de la República, Carlos Andrés Pérez — mayo 1993 - bajo cargos de corrupción. Este hecho, por supuesto, no significó la superación de la crisis política, sino más bien la expresión de su agudización, por tanto la misma persistió, ya que en el país se vivió una situación de muy precaria gobernabilidad a lo largo del tiempo restante para la conclusión del quinquenio truncado.

El agotamiento del sistema político venezolano también se manifiesta con los resultados de las elecciones presidenciales de diciembre de 1993. Es un hecho relevante en la política venezolana, como es la primera derrota electoral de los partidos tradicionales (AD y Copei), quienes, desde 1958, venían alternándose en el control del gobierno y de las instituciones públicas; además, ambos encarnaban las dos primeras fuerzas políticas en el movimiento sindical, y estas elecciones representaron un mecanismo de legitimación de la democracia. El resultado electoral de 1993 fue capitalizado por un viejo dirigente fundador del partido socialcristiano, Rafael Caldera, quien se había separado del partido y aprovechó el fallido golpe militar para repotenciar su hasta entonces débil candidatura presidencial, deslindándose de las fuerzas políticas tradicionales. Pero su triunfo, con el apoyo de una multitud de pequeñas organizaciones partidistas ${ }^{7}$, se trató de una precaria victoria, con apenas el 30\% de una población electoral en donde la mayoría era la abstención, que alcanzó el $39,84 \%$, la más alta en la historia electoral moderna de las elecciones presidenciales. Se pasó de un bipartidismo con un electorado participativo a un multipardisimo con baja participación electoral (Maingon, 1995: 188). Este hecho colocó al gobierno naciente en situación de debilidad ante los órganos parlamentarios, las gobernaciones y las alcaldías, que seguían bajo el control de los dos partidos políticos tradicionales. Por tanto, no se emprendieron las profundas reformas políticas necesarias que contribuyeran a salir de la crisis. El país continuó deteriorándose. Un nuevo programa de ajuste — «La Agenda Venezuela» - fue implantado en 1996, pero factores asociados a la baja de los precios del petróleo, junto a la debilidad gubernamental, no pudieron solventar la crisis general. El Gobierno, en sus dos últimos años, promovió y logró

7. El ingenio popular denominó la coalición que apoyaba su candidatura «el chiripero», el nombre viene de chiripa, especie pequeña de la cucaracha, que políticamente quiso significar un conjunto de miniorganizaciones partidistas, en donde destacaba el Movimiento al Socialismo, fuerza que había obtenido un 7\% en las elecciones pasadas de 1988. 
articular un proceso de diálogo social, como vía para emprender reformas laborales, pero el grado de desconexión entre dirigentes y representados por parte de los actores de la producción conspiró en contra de la voluntad del Ejecutivo. Además, el grado de exclusión existente en el ámbito de la fuerza de trabajo, sin vínculos estables con el mercado laboral y con la cúpula sindical, plantean un problema de viabilidad y legitimidad a todo esfuerzo de concertación que ignore a tan amplias capas sociales.

Por ello, en la renovación electoral de diciembre de 1998, emerge con una contundente victoria electoral $-56 \%$ del electorado votante-, arrollando a todos los estamentos políticos tradicionales, el líder de la asonada militar de febrero de 1992, Hugo Chávez, acompañado de una nueva organización política integrada por civiles tradicionalmente de izquierda y militares, en una coalición denominada Polo Patriótico, predominando en la misma el partido Movimiento V República, fundado y liderado por el mismo presidente. Este nuevo liderazgo sí contó con suficiente apoyo electoral para plantearse y poder llevar a cabo cambios políticos radicales. La elección de la Asamblea Nacional Constituyente y la correspondiente elaboración de una nueva constitución nacional, se convierten en las metas políticas fundamentales, las cuales fueron alcanzadas, lo que brindó al Gobierno un masivo respaldo popular. Los eventos electorales nacionales celebrados entre diciembre de 1998 y 1999, en un año, evidencian que las organizaciones políticas que tradicionalmente habían dominado la escena política casi desaparecen del escenario. Los nuevos actores políticos en función del gobierno evidenciaron una sintonía con el electorado que mantuvo márgenes de apoyo cercanos al setenta por ciento en las tres elecciones realizadas en un solo año: referéndum para decidir convocatoria a una asamblea constituyente —abril—, elección de los constituyentistas — julio- y referéndum para decidir sobre el nuevo texto constitucional — diciembre de 1999.

La amplia mayoría conseguida por el Polo Patriótico en las elecciones de la Asamblea Constituyente le permite diseñar una nueva constitución, en donde no tuvo necesidad de hacer concesión alguna a las fuerzas opositoras. El proceso fue acelerado y el Gobierno contó con la ventaja de que en una asamblea constituyente de 132 miembros, tan sólo seis - 6- fueron electos fuera de la fórmula gubernamental, verdaderamente un dominio total. Aunque es necesario destacar que el carácter absolutamente uninominal del sistema electoral determinó que, con un $66 \%$ de votos, el Gobierno obtuviera el $95 \%$ de los constituyentistas. Entre agosto y diciembre, en una marcha forzada, acelerada y zigzagueante, se discute y se aprueba la nueva constitución. La interferencia del presidente fue abierta, en el sentido de hacerles cambiar contenidos en asuntos relevantes, luego de que los mismos asambleístas habían llegado a un determinado consenso.

En todo caso, esta constitución, a diferencia de la derogada, la de 1961, nace bajo un clima poco consensual, ya que la propia convocatoria al referéndum que consultó a la nación sobre este texto, tuvo una abstención del 55\%. Quienes votaron, se repartieron en un 70\% por el sí y el resto por el no ( $E l$ Nacional, 16-12-1999). Así que, al final, un tercio de la población afirmó la 
nueva constitución. A los dos años de su vigencia, el presidente y la oposición señalan reservas en cuanto a su contenido.

Los rasgos que caracterizan a esta nueva constitución son el fortalecimiento del presidencialismo, lo cual se opone a una crítica que ya venía desarrollándose desde el momento que se dieron los primeros pasos hacia la descentralización; consecuentemente, se produce un debilitamiento de este proceso, al replantear nuevamente la centralización de las decisiones en el gobierno nacional. Un rasgo que se ha mostrado sumamente peligroso es el haber llevado la política a los cuarteles, hecho que hoy se afirma como contraproducente para el ejercicio institucional de las Fuerzas Armadas.

En los asuntos sociales y laborales, se fijan ambiciosas metas que, dadas las condiciones económicas del país, tienen un carácter programático de ejecución imprecisa en el tiempo. Tales son los contenidos en el ámbito de la seguridad social. Se incorpora el trabajo del hogar a los beneficios de la seguridad social, se establece la pensión universal, independientemente de la contribución. En esta materia, la orientación de la constitución se le califica de populista, ya que no hubo en el debate referencias a la viabilidad ni al realismo de los beneficios sociales incluidos.

\section{Cuarta etapa: nuevo bloque en el ejercicio del poder político. Composición y mutación}

Con la entrada en vigencia de la nueva constitución, se plantearon problemas desde su inicio, al publicarse cuatro distintas versiones, derivadas del carácter hegemónico e inconsulto como se manejaron estos asuntos en la Asamblea Constituyente. Las modificaciones inconsultas se atribuyen a personas del mismo gobierno, que argumentaron la revisión por necesidades de estilo, pero que modificaron el contenido y la interpretación de normas constitucionales. Inmediatamente, se iniciaron procesos ante el máximo tribunal del país, para dirimir cuál de las versiones era la legítima.

La nueva constitución exige la relegitimación de los poderes, y aquí se plantean nuevas elecciones, que vuelven a dar una aplastante mayoría al MVR y sus aliados. Es así que Hugo Chávez nuevamente triunfa electoralmente en la Presidencia, derrotando a un excompañero del golpe de 1992 - Arias Cárdenas-. Igual victoria ocurre en el poder legislativo, de tal manera que, cuando toca conformar los nuevos poderes judicial, electoral y moral, éste último comprende el fiscal general, la contraloría y el defensor del pueblo, sucede la imposición de mayorías dejando de lado los procesos de consulta a la sociedad civil planteados en el texto constitucional. Los miembros del máximo tribunal del país argumentaron en su favor que no tenían que someterse al dictamen ni a la evaluación señalada en la nueva constitución.

En la medida que avanzaba el gobierno, el bloque político que lo constituía se ha venido depurando. Para el segundo año de su mandato, se identifican en su integración: 
- Parte del grupo de oficiales que conformaron los alzamientos militares de 1992.

- El Partido Movimiento V - quinta - República, es el gran partido oficialista, presidido por el propio presidente Hugo Chávez, conformado por ex militares e izquierdistas.

- Segmentos de la izquierda radical tradicional, entre los cuales aparecen organizaciones como el Partido Patria para Todos - PPT—, cuya fuerza electoral alcanzó apenas el $1 \%$ en las elecciones del 2000 , apenas cuentan con un parlamentario en la Asamblea Nacional ${ }^{8}$. El Partido Comunista de Venezuela y el Movimiento Electoral del Pueblo, con fuerzas electorales incluso menores que la del PPT, eran partidos que estaban casi desaparecidos, pero revivieron con el chavismo, que había resultado ser una suerte de portaaviones que ofrecía espacio seguro para llegar al Parlamento y a los cargos públicos de elección popular.

Este bloque de poder manifiesta que gobierna, en primer lugar, para los sectores más pobres de la sociedad, constituidos por trabajadores de bajos ingresos, desempleados e informales. ¿Qué se les ha otorgado?: a través del Plan Bolívar, administrado por las Fuerzas Armadas, se han creado empleos temporales y precarios. Por medio de diversas instituciones sociales y financieras de reciente creación, se han redistribuido recursos económicos para el fomento de microempresas. Desde el propio Gobierno y el MVR se ha fomentado, a partir del 2001, la constitución de los círculos bolivarianos ${ }^{9}$, colectivos sociales para organizar a las personas identificadas con el gobierno, brindándoles ayudas económicas de tipo asistencialista. A cambio, estos círculos participan activamente en movilizaciones y actos públicos de apoyo al gobierno. Se advier-

8. La Asamblea Nacional la conforman 165 asambleístas o diputados.

9. A estas organizaciones se las compara con los llamados Comités de Defensa de la Revolución - CDR - que existen en Cuba, promovidos desde el partido del gobierno y el propio gobierno. Algunas de las acciones violentas ejercidas en contra de sectores e instituciones de la oposición son reivindicadas por los círculos bolivarianos. De todo, lo más grave son los señalamientos en contra de connotados miembros de los círculos en las agresiones contra la marcha del 11 de abril, que produjo un saldo de 19 muertes y cientos de heridos.

En una lectura de revisión del presente documento realizada en marzo 2004, previo a su publicación, el autor cree necesario señalar, que en cuanto a organización de los sectores que constituyen la base social del régimen, se han emprendido importantes iniciativas, llamadas por el gobierno «Misiones» o «Planes», en tal sentido se señala: la Robinson I y la Robinson II, cuyo objetivo es alfabetizar y proveer edución básica, siguiendo metodología suministrada por el Gobierno de Cuba; la Rivas, que buscar completar el bachillerato o educación media; la Sucre, que provee educación superior; el Plan «Barrio Adentro» que lleva asistencia médica a los barrios más pobres, con participación de personal médico y paramédico procedente de Cuba. Se han anunciado la Misión «Guaicaipuro», para atender a la población indígena y la Misión "Vuelvan Caras» para atender a desempleados. En todos estas misiones, se provee apoyo económico monetario a los participantes, en algunos casos equivalente al salario mínimo. Igualmente se ejerce control a través de los partidos oficialistas y de instituciones gubernamentales, que demandan lealtades partidistas e ideológicas de quienes son beneficiarios de estos programas. 
te que estas organizaciones han venido jugando un polémico papel en la vida pública por los métodos agresivos que emplean contra quienes identifican como opositores al gobierno.

En la medida que el gobierno viene desarrollando su administración y se implementan las instituciones de la nueva constitución, el gobierno viene perdiendo aliados de la fase inicial gubernamental, que le acompañaron en la campaña de 1998 y el primer año de gestión, 1999.

¿Quiénes se han separado? ¿Cuáles han sido sus razonamientos?

a) Militares más identificados con el pluralismo y la convivencia civil, incómodos con el discurso agresivo del gobierno a toda disidencia y con el papel desmilitarizante de funciones previstas en el Plan Bolívar, que es interpretado como una desnaturalización del papel de las Fuerzas Armadas, al colocar en papel prioritario las funciones sociales sobre las propiamente militares ${ }^{10}$. Son comunes en las funciones de este plan, la organización de mercados populares, de jornadas de vacunación, de mantenimiento y mejora de infraestructuras educativas y de salud. Todas estas actividades se llevan a cabo en zonas en donde viven personas de bajos ingresos. También son objeto de críticas por parte de este sector de militares, las relaciones del gobierno con la guerrilla colombiana de las FARC. Hay que recordar que existen antecedentes de enfrentamientos de las FARC con unidades regulares del ejército venezolano en zonas fronterizas ${ }^{11}$.

b) Importantes medios de comunicación y comunicadores que habían apoyado la campaña de Chávez. Dos medios muy influyentes en la opinión pública venezolana, como el periódico El Nacional ${ }^{12}$ y el canal televisivo Venevisión, acompañaron a Hugo Chávez en su campaña y en el inicio de su gobierno, pero al poco tiempo se produjo una ruptura, que se ha ahondado a medida que avanza el tiempo. A lo largo del gobierno, han sido los medios de comunicación quienes han liderado la oposición al gobierno, dando lugar a frecuentes roces entre activistas de éste y los medios. El gobierno argumenta que ha sido permisivo y respetuoso con la libertad de prensa, a tal punto que no hay un periodista preso, sin embargo, los medios y los periodistas llaman la atención de las agresiones de las cuales son objeto en el cumplimiento de sus funciones, por parte de grupos adictos al gobierno, que son reflejo del discurso agresivo y acusador del presidente. Los gre-

10. Los comandantes Francisco Arias Cárdenas, José Urdaneta y Joel Chirinos fueron los otros comandantes que junto a Hugo Chávez lideraron el golpe de febrero de 1992, pero actualmente forman parte de este grupo de militares que se han distanciado del presidente por las razones expuestas.

11. Luego del ataque del 11 de septiembre a sitios estratégicos de los EEUU, la presión internacional por calificar de terroristas, entre otros grupos, a las FARC y al ELN, ha sido evadida por el gobierno venezolano, quien argumenta que no tiene intenciones en entrometerse en los asuntos internos colombianos.

12. Una directiva de este medio de comunicación impreso — Carmen Ramia de Otero- formó parte del primer gabinete del presidente Hugo Chávez. 
mios de periodistas han consignado denuncias ante la Comisión Interamericana de Derechos Humanos, las cuales han sido acogidas y se han emitido recomendaciones al Gobierno venezolano de garantizar el ejercicio de la libertad de prensa.

c) Intelectuales y académicos que le dieron lustre a las campañas electorales iniciales. Especialmente para la conformación de las listas en las elecciones de la Asamblea Constituyente, el gobierno apeló a intelectuales que ya le acompañaban en la campaña electoral de $1998^{13}$. El tema de la intolerancia con la disidencia y las formas autoritarias del manejo presidencial determinaron estos alejamientos.

d) La mayoría del Movimiento al Socialismo - MAS - . Este partido sacrificó su unidad inicialmente al decidir apoyar la candidatura de Hugo Chávez en 1998, de ahí que perdió en esa ocasión el segmento de mayor experiencia política. La mayoría de ellos fundaron un nuevo partido UNION-y otros quedaron como independientes de oposición ${ }^{14}$. Pero a lo largo del gobierno, fue siendo dejado de lado en las más importantes decisiones, no obstante su importante fuerza parlamentaria y el control de varias gobernaciones. Esto determinó una nueva división del MAS entre oficialistas que se mantienen apoyando al gobierno y el ala mayoritaria que se fue a la oposición ${ }^{15}$.

e) Una parte del Partido Patria para Todos —PPT—. Como se señaló, este partido acompañó al Polo Patriótico en las elecciones de 1998 y 1999, pero ya en la relegitimación de los poderes en 2000 se producen diferencias con Hugo Chávez y es puesto a un lado. Éste es un partido con una población electoral reducida, pero cuenta con dirigentes experimentados, se autocalifica como un partido de cuadros con cierta influencia en algunos segmentos laborales, por ello, con motivo de las elecciones sindicales, se produce un acercamiento del gobierno, al carecer de candidatos y cuadros en este campo, aceptándose apoyar a un candidato del PPT para la presidencia de la CTV - Aristóbulo Isturiz-, al salir éste derrotado, se produce en compensación un reingreso del PPT en las filas del gobierno, trayendo consigo una división del partido ${ }^{16}$.

13. Destacan los constituyentistas Herman Escarrá, Jorge Olavaria, Ricardo Combellas, Ángela Zago. También fueron a formar filas con la oposición influyentes intelectuales como Javier Elechiguerra, ex procurador, y Ernesto Mayz Vallenilla, ex rector de la Universidad Simón Bolívar.

14. Destacan los dos líderes fundadores del MAS en 1971, Teodoro Petkoff y Pompeyo Márquez, quienes mantienen su actividad emitiendo opiniones e influyendo a través de sus frecuentes apariciones públicas. Petkoff dirige el vespertino Tal Cual.

15. Encabezada por Felipe Mujica como presidente del partido y Leopoldo Puchi, como secretario general. Al final la fracción oficialista optó por fundar un nuevo partido, llamado «Podemos», que nuevamente al poco tiempo sufrió otra escisión, que trajo la pérdida de dos parlamentarios (Rafael Simón Jimenez y Luis Salas), de los nueve que tiene esta fracción.

16. Su secretario general, Pablo Medina, y el dirigente Alberto Muller, entre otros, se separan del partido. Quienes se quedan con el ala oficial disfrutan de una amplia porción de poder en 
f) Empresarios que exteriorizaron su desencanto con el bipartidismo apoyando a Chávez en un primer momento. Las relaciones del empresariado fueron difíciles con el gobierno previo al de Hugo Chávez, de aquí que un segmento importante de éstos se inclinó por apoyarlo en la campaña electoral de 1998. En la medida que el gobierno no atendió el área económica, que continuó deteriorándose, y al empezar a tomar decisiones sobre política económica que tocaron intereses fundamentales del empresariado, en el marco de poderes extraordinarios otorgados por la Asamblea Nacional, se produjeron nuevos distanciamientos.

g) El mundo universitario. En su interior se mostraron simpatías a la candidatura de Hugo Chávez, aunque en las universidades autónomas que realizan elecciones para escoger sus autoridades ${ }^{17}$, las fuerzas políticas que simpatizan con el gobierno no han ganado en ninguna universidad, incluso en algunas no presentan candidatos por no contar con suficientes fuerzas. La toma violenta de instalaciones del gobierno universitario en la UCV por parte de estudiantes y personas ajenas a la institución, con el visible apoyo de personeros gubernamentales (vice-presidenta y ministro de la Secretaría), levantó mayores oposiciones dentro del mundo universitario. En las universidades experimentales, que, entre otras características, no eligen directamente a sus autoridades, sino que éstas le son impuestas, los incipientes mecanismos de consulta que se venían poniendo en práctica fueron puestos de lado por las autoridades nacionales de educación superior, generando fricciones internas ${ }^{18}$.

h) Disensiones dentro de la fracción parlamentaria chavista. Con ocasión de la elección de la junta directiva de la Asamblea Nacional en enero de 2002, quedó en evidencia la existencia de disensiones dentro de la fracción oficialista, que, si bien conservó su mayoría, ésta se redujo sensiblemente. La disidencia dentro de la fracción ha sido manejada con dureza por el sector más sectario del gobierno, llamado popularmente "los talibanes», de ahí que algunos parlamentarios han empezado a distanciarse. La fracción disidente asume una postura conciliadora que valora la necesidad de mantener diálogos con las otras fuerzas políticas. El líder de esta fracción, el entonces ministro de Interior y Justicia, Luis Miquilena, sale del gobierno en enero del 2002 y asume posiciones de ruptura con el MVR y de coincidencia con la oposición.

el gobierno, si se toma en cuenta que militantes pepetistas están al frente de PDVSA (la petrolera oficial), de las carteras de Trabajo, de Salud y Desarrollo Social, de Educación, Cultura y Deportes.

17. Aparte de las universidades autónomas, el sector público cuenta con las universidades experimentales, que son regidas por regulaciones diferentes al menos en lo referente a la elección de sus autoridades, ya que en éstas últimas es el gobierno quien las nombra, en algunos casos se venían iniciando procesos de democratización que ahora se han congelado.

18. Los casos más notorios ocurrieron en las universidades Simón Rodríguez, Francisco de Miranda, Rómulo Gallegos y la Universidad de los Llanos. 
i) Militares institucionales: el golpe por gotas "goteao" — enero y febrero de 2002 - Varios oficiales de alto rango — generales, coroneles y vicealmirantes - manifestaron públicamente sus discrepancias con el manejo del gobierno, pidiendo la renuncia del presidente. Sus discrepancias son similares a las indicadas en el punto $a$ ), agregándose las críticas a las relaciones del gobierno de Hugo Chávez con el gobierno de Fidel Castro, especialmente el suministro de petróleo en condiciones lesivas al patrimonio nacional. Además, destacan las malas relaciones sostenidas con los socios naturales del gobierno venezolano, en el fondo se refieren a las tensas conexiones con el gobierno de los EEUU y de Colombia.

Hay que destacar que se mantienen amplias capas de los sectores más pobres de la sociedad identificados con el gobierno. Desempleados, informales, en general buena parte de los sectores excluidos sienten que el gobierno de Chávez los protege, y sintieron mayor identidad cuando el gobierno provisional de Carmona emitió los autoritarios decretos que cancelaban todos los poderes. Estos sectores carentes de un liderazgo en el amplio espectro de la oposición, continúan viendo en Hugo Chávez su redención ${ }^{19}$.

\section{Gobierno y movimiento sindical}

Existe, desde los nuevos actores políticos en el ejercicio del poder estatal, una abierta intención de producir modificaciones en el cuadro sindical venezolano, y con ello probablemente en el funcionamiento de las relaciones laborales. Las ventajas de haber contado con amplias mayorías en los órganos elaboradores de los instrumentos normativos, como fue el caso en la Asamblea Constituyente y ahora en la Asamblea Nacional, ha permitido al gobierno y sus aliados emprender modificaciones significativas en los aspectos normativos. La sociedad en general tuvo una actitud de expectativa ante estas intervenciones normativas, por el grado de descomposición y exclusión alcanzado en los últimos veinte años, en donde las organizaciones sindicales fueron percibidas como corresponsables de esta situación, por ser apéndices de los liderazgos partidistas que son señalados como usufructuarios del poder y ejecutores de las desviaciones que contribuyeron al deterioro general de las instituciones públicas. Además, hicieron muy poco para atender a los sectores excluidos, a pesar del volumen de personas incluidas en el mismo. Ello ofrece bases ciertas para comprender el porque hubo una actitud tolerante de amplios sectores de los trabajadores, ante los planteamientos oficialistas de intromisión y protagonismo en el mundo sindical. Pero, en vista de que el gobierno promovió iniciativas de intervención sindical de orientación más bien autoritaria, como se analizará más adelante, la percepción general de aceptable pasó a ser más bien de criticismo.

19. A pesar de todo el desgaste por los problemas económicos y el deterioro político-social, Hugo Chávez sigue siendo el líder con mayor puntuación en las encuestas de popularidad. La empresa Datanalisis le asigna el 33\%, aventajando por veinte puntos a su más cercano perseguidor, Luis Vicente León (El Carabobeño, 30-9-2002, C-5). 


\section{Relaciones de trabajo: las primeras derrotas oficialistas. ¿Cuál ha sido el enfoque del gobierno de Hugo Chávez con los temas de las relaciones laborales?}

A lo largo de los dos primeros años de gobierno, lo característico de las contiendas en donde participaba el gobierno eran sus contundentes victorias. Las primeras confrontaciones que derrotaron posiciones del gobierno ocurren en el ámbito de las relaciones de trabajo.

En primer lugar, y desde la campaña electoral presidencial a lo largo de 1998, Hugo Chávez venía planteando la necesidad de cambiar las estructuras sindicales. Luego de su triunfo, el mismo mensaje fue exteriorizado por su primer ministro de Trabajo. Sin embargo, la Confederación de Trabajadores de Venezuela - CTV_- poco después del triunfo electoral de Hugo Chávez, le envió una carta manifestándole su disposición al diálogo y ofreciéndole su apoyo ( $E l$ Nacional, 11-12-1998). Un reconocimiento del nuevo escenario. La arrogancia cetevista - CTV - de otros tiempos desapareció. El Gobierno ignoró este gesto sindical. Evidentemente, la lucha en contra de la CTV estaba anunciada y ratificada.

Una primera manifestación de la hostilidad gubernamental hacia el sindicalismo cetevista se exterioriza en la suspensión de los aportes gubernamentales a los sindicatos ${ }^{20}$. Sin embargo, el tema de las relaciones laborales más controversial ha sido el de la libertad sindical, que incluso ha determinado la visita al país de misiones de la OIT, convocadas por el movimiento sindical, y la denuncia de violaciones ante su Comité de Libertad Sindical. Estas misiones han mediado en la búsqueda de una aplicación efectiva de los convenios 87 y 98 relativos a la libertad sindical y la negociación colectiva.

Evidentemente que el gobierno, vía Ministerio del Trabajo, ha puesto en práctica una política favorecedora del cambio en la composición política de los liderazgos en los sindicatos de base. Pero más llamativa y evidente, el carácter de una nueva política en la relación con los sindicatos, se observa en la posición del Ministerio del Trabajo ante los reclamos de sectores laborales descontentos con el funcionamiento de las organizaciones sindicales tradicionales, que se ha traducido en una amplia receptividad a planteamientos que cuestionan algunas conductas sindicales tradicionales. El eje de esta política consiste en la asunción de una posición vigilante ante los procesos de elecciones sindicales, por parte del Ministerio del Trabajo. Tradicionalmente, la renovación de los liderazgos sindicales ha sido un proceso carente del dinamismo que sugiere la legislación laboral venezolana. Tres factores pueden señalarse para explicar esta falta de dinamismo:

20. Esta suspensión tiene una lectura en positivo, como lo manifiesta Alfredo Ramos, responsable sindical de la Causa R y miembro del nuevo Comité Ejecutivo de la CTV, quien lo reconoce favorablemente: «Afortunadamente, el gobierno suprimió el financiamiento destinado a los sindicatos. Eso era una aberración que trajo como consecuencias, corruptelas y poca capacidad de lucha en el movimiento sindical» (El Carabobeño, 13-5-2002, p. C5). 
- El primero radica en el interés empresarial, en el mantenimiento de determinadas estructuras sindicales, con las cuales se ha mantenido un cierto statu quo que ha facilitado a su modo el desenvolvimiento de las relaciones colectivas de trabajo.

- El segundo factor radica en los propios liderazgos sindicales existentes, cuya perpetuación y permanencia aspiran que no sea interrumpida. Los beneficios de la condición de dirigentes sindicales, recibidos del statu quo gubernamental y empresarial, tenían carácter prebendario.

- Y, finalmente, la Administración Pública del Trabajo ha carecido de voluntad para demandar el cumplimiento de las normas expresas que sobre elecciones sindicales están establecidas en el ordenamiento laboral venezolano.

¿Cómo explicar esa falta de voluntad? Se explica por los vínculos existentes entre gobiernos, partidos y movimiento sindical, que colocaba al primero en posición de vehículo al servicio del segundo, determinando una administración pública del trabajo sesgada a favor de las corrientes oficialistas en el manejo del movimiento sindical. Es en este factor en donde se aprecian manifestaciones que marcan distancia con comportamientos anteriores del Ministerio de Trabajo. Se trata de nuevos actores políticos partidistas que aparecen en el escenario sindical, desde la Administración del Trabajo y prestando el apoyo gubernamental a corrientes emergentes en el movimiento sindical.

La evidencia de un comportamiento que abre posibilidades a una libertad sindical que facilita el acceso a nuevos actores, se puede conocer al analizar varios casos ocurridos a lo largo de 1999, en el desenvolvimiento de la renovación de los liderazgos sindicales. En los procesos electorales a lo largo del 2000 y el 2001 ya estaba vigente la nueva constitución, la cual es altamente intervencionista sobre estos procesos, al colocar bajo el control de un organismo externo — el Consejo Nacional Electoral- los procesos electorales sindicales.

Durante un largo período se hizo costumbre que las directivas sindicales fuesen ratificadas sin hacer elecciones, poniendo en práctica un mecanismo no previsto en la legislación, denominado "reestructuración de la directiva». Consistía en hacer una asamblea y ratificar a los directivos existentes. Evidentemente, este procedimiento coartaba toda posibilidad de renovación y alternabilidad directiva. Las autoridades del Ministerio de Trabajo convalidaban estas prácticas, al ser receptoras de las actas que lo reseñaban y no emitir cuestionamiento alguno, a sabiendas de la violación de la libertad sindical que ello suponía.

Durante 1999, fueron presentados varios casos de reestructuración de juntas directivas sindicales ante las inspectorías de Trabajo en varias ciudades importantes del país, pero a los que los presentaron les fue planteada la exigencia de realizar elecciones siguiendo las consideraciones establecidas en el ordenamiento vigente, es decir, elecciones directas y secretas. Igualmente, se revisaba si se atendían las reglas que las propias organizaciones sindicales habían elaborado en la oportunidad de su legalización o en eventos posteriores dirigidos a modifica- 
ciones reglamentarias en materia electoral. Se trata de efectuar un proceso electoral que dé oportunidades de participación, en igualdad de condiciones, al conjunto de los trabajadores. Por supuesto que esta política lleva implícito el propósito de que en el ámbito sindical se den procesos de renovación que ya han ocurrido en otros ámbitos de la sociedad venezolana.

\section{Huelga petrolera}

Con motivo de las negociaciones del convenio colectivo petrolero en septiembre de 2000 , se produce una huelga petrolera que derrota las pretensiones del gobierno de imponer un contrato colectivo unilateralmente, desconociendo a las organizaciones sindicales más representativas - Fedepetrol y Fetrahidrocarburos-y favoreciendo la constitución de nuevos actores sindicales, aspirando con ello a desplazar a las centrales anteriores. Resalta la apertura brindada por el Ministerio del Trabajo, para favorecer la incorporación de un nuevo actor sindical en las relaciones laborales del sector petrolero. Se trata de una organización que fue legalizada en 1994, pero sus intentos por incorporarse a los procesos de negociación se habían frustrado, ya sea por la oposición empresarial o la sindical tradicional. Al fin, en las negociaciones que se llevan adelante desde el pasado noviembre de 1999, el Sindicato Nacional de Trabajadores Petroleros — SINTRAIP — logra sentarse en la mesa de negociaciones del convenio colectivo, junto a las organizaciones tradicionales, quienes por décadas se habían opuesto, junto a las empresas, a la incorporación de cualquier otro actor sindical.

La derrota oficialista en esta huelga lleva a la destitución del presidente de la petrolera oficial - PDVSA- Se produce, entonces, el primer acto recuperativo del movimiento sindical, que, desde la llegada de Hugo Chávez al poder, había mantenido un perfil bajo, asociado a su baja credibilidad en los años precedentes. Igualmente, juega un papel estelar el dirigente Carlos Ortega, quien estaba casi retirado al haberse separado voluntariamente de su cargo de presidente de Fedepetrol. Su papel de liderazgo en esta huelga lo coloca en el centro de la oposición sindical al régimen. Por ello, cuando se plantean las elecciones sindicales nacionales — septiembre de 2001—, resulta el candidato con mayores posibilidades, y es el ganador de la Presidencia de la Confederación de Trabajadores de Venezuela - CTV.

\section{El referéndum sindical}

La expresión más manifiesta de la política de intervención emprendida por el oficialismo, para hacerse un espacio en el movimiento sindical, fue la aprobación de un referéndum sindical. La Asamblea Nacional con la mayoría oficialista lo justificó así:

La Asamblea Nacional, en fecha diez (10) de octubre de 2000, en el Palacio Federal Legislativo, motivada a canalizar, impulsar y facilitar los procesos de 
transformación social y política; inspirada en los artículos 95 y 96 de la Constitución de la República Bolivariana de Venezuela, considerando que la transformación del movimiento sindical venezolano es un tema de interés nacional, acordó convocar un referendo nacional basado en los artículos 70 y 71 del mismo texto constitucional, para dar inicio a la transformación e implementación de los deberes, derechos humanos y garantía consagrados en la misma.

A los electores, que en esa ocasión ya habían sido convocados a un acto electoral programado en el marco de la agenda de renovación de los poderes, como era la elección de los gobiernos locales (alcaldes y concejales), se les entregaría una boleta contentiva del referéndum sindical, con la pregunta siguiente:
¿Está usted de acuerdo con la renovación de la dirigencia sindical, en los próximos 180 días, bajo Estatuto Especial elaborado por el Poder Electoral, conforme con los principios de alternabilidad y elección universal, directa y secreta, consagrados en el artículo 95 de la Constitución Bolivariana de Venezuela, y que se suspendan durante ese lapso en sus funciones los direc- tivos de las Centrales, Federaciones y Confederaciones Sindicales estableci- das en el país?

El resultado de este referéndum fue un marcado fracaso, la primera derrota electoral del gobierno bolivariano, ya que apenas participó un $22 \%$ de la población votante.

Desde el mismo momento que el Gobierno y el MVR plantearon la convocatoria al referéndum, éste produjo malestar en diversos sectores, porque involucraba en asuntos sindicales a toda la población votante, es decir, los militares, los empresarios, los miembros del clero, en fin, toda la población electoral votaría por los asuntos que corresponden sólo al movimiento sindical. Incluso votarían los extranjeros, sin las limitaciones que impone la legislación laboral, que exige diez años mínimos de residencia en el país, para acceder a funciones directivas en los sindicatos. En cambio, los menores trabajadores, a quienes la legislación del menor les permite votar en su organización sindical, en el referéndum no pudieron hacerlo por no tener la edad mínima para votar - 18 añosEn fin, unos, tenían la opción de votar más allá de su vinculación con el sector, otorgándoseles derechos que no les correspondían en los asuntos propios del seno de las organizaciones sindicales, pero también estaba el caso opuesto de negar el derecho a quienes por las leyes específicas sí lo tienen.

¿Al final, qué ocurrió? La respuesta abstencionista fue la lección que le dio la sociedad al oficialismo, a los promotores del referéndum, un mecanismo que incluso contó con el rechazo de aliados gubernamentales, como fue el caso del sindicalismo del Movimiento al Socialismo y representantes del Frente Constituyente de Trabajadores ${ }^{21}$. También los empresarios lo rechazaron públi- 
camente $^{22}$. El peligro de que se generalizara la pretensión gubernamental de intervenir en los asuntos internos de las organizaciones gremiales, junto, además, a la rudeza con la cual se arrinconaba a un aliado en el sistema laboral tradicional justificó plenamente la preocupación empresarial.

Los argumentos legales esgrimidos por los opositores al referéndum destacaban la violación de los convenios 87 y 98 de la OIT, y la propia Constitución, en su artículo 23, que hace referencia a la preeminencia de los convenios internacionales firmados por la república.

Las consecuencias pos referéndum determinaron la separación de los directivos de las confederaciones y federaciones, lo que trajo consigo un vacío en los órganos de segundo y tercer grado del movimiento sindical, contribuyendo a su desarticulación. Sin embargo, el liderazgo cetevista adoptó una estrategia que resultó acertada, como fue la creación de la Junta de Conducción Sindical, integrada, en principio, por las tendencias que hacían vida en las organizaciones sindicales, pero luego se incorporaron otras tendencias de orientación de izquierda: Frente Constituyente de Trabajadores, Bandera Roja y, finalmente, el Nuevo Sindicalismo-Causa R, resultando una integración más amplia que la del propio comité ejecutivo de la CTV. La mayoría de sus miembros eran asesores del movimiento sindical con formación universitaria y buena imagen, no asociados a problemas de corrupción. Entre sus logros, se destacan haber preservado la institucionalidad sindical, aguantar el impacto de las victorias de Hugo Chávez, así como de sus agresiones, y sustituir a una dirección agotada que venía de 1995, ya casi vencido su período.

Aunque el referéndum, según su texto, no tuvo influencia directa en las organizaciones de base, es decir los sindicatos, el hecho de tener que ceder sus posiciones - no todas las organizaciones de segundo y tercer grado lo hicieron- estimuló posiciones y actitudes de desconocimiento sindical por parte de empleadores - privados y públicos — interesados en tomar ventaja de la turbulencia existente.

\section{Recuperación del movimiento sindical: el hostigamiento gubernamental}

El referéndum sindical, paradigma de la intromisión gubernamental y la persistencia de la política oficial de agresión al sindicalismo, ayudó a este movimiento, que empezó el período gubernamental de Hugo Chávez con un bajo perfil por su propio desprestigio, a recuperarse, de manera que, gracias a la victimización, ha sabido sacar provecho de esa situación.

La concurrencia de las más importantes fuerzas al registro electoral otorgó a la Confederación de Trabajadores de Venezuela su relegitimación. Hay que destacar que la elección por la base de todos los cargos de la confederación sindical es un hecho inédito en el país. Incluso en el movimiento sindical

22. La posición la expresó el presidente (E) de FEDECAMARAS —organización cúpula de los empresarios- Pedro Carmona, en El Carabobeño, 18-11-2000. 
internacional, lo usual es que estos cargos sean la resultante de elecciones de segundo o tercer grado. También se señala un incremento del número de mujeres en posiciones de liderazgo sindical y una mayor participación de jóvenes ${ }^{23}$.

El Registro Electoral Sindical, constituido en el Consejo Nacional Electoral, es publicado por este organismo indicando que, de 2.974 organizaciones sindicales, realizaron elecciones 2.852 sindicatos, de las cuales 2.044 estaban afiliadas a la CTV, 49 a CGT, 34 a Codesa y 847 no confederadas. La CTV constituye el $70 \%$ de los sindicatos, con un porcentaje mayor en cuanto a la población sindicalizada, ya que incluye a los de mayor tamaño (CNE, 2002). Es importante también destacar que el registro electoral sirvió para precisar la tasa de afiliación sindical, que se ubicó en el 14\% de la población económicamente activa, que, evidentemente, ha venido bajando por el deterioro del mercado laboral.

El desarrollo de las elecciones es un proceso accidentado, ya sea por el intervencionismo gubernamental o por la pretensión del sindicalismo tradicional de persistir en la puesta en práctica de mecanismos electorales poco transparentes, en donde las mayorías sindicales atropellaban a las pequeñas fuerzas. Los dirigentes de la CTV han puesto en escenarios internacionales sus denuncias, como por ejemplo en la OIT y en las centrales ORIT-CIOSL y CLAT-CMT, organizaciones continentales y mundiales de afiliación del sindicalismo.

En la campaña electoral sindical se planteó la necesidad de organizar un congreso de los trabajadores que elabore su visión del país y determine las etapas para su alcance; que modernice sus estructuras y los ajustes necesarios para un modelo económico y social viable y autosustentable; que redefina sus relaciones y alianzas con los más importantes sectores del país; que dé respuestas a la incorporación de los sectores no estructurados; que otorgue una mayor apertura para los profesionales, los jóvenes y las mujeres; que elabore su plataforma reivindicativa global y sectorial, de corto, mediano y largo plazo; en fin, que refunda sus plataformas, propuestas y estructuras, lo cual es un asunto pendiente. La crisis y su agudización solapa este compromiso, pero en el fondo el futuro del movimiento demanda cumplir con esta tarea.

Nuestro análisis de este proceso sindical es que, a pesar de los aspectos turbulentos y accidentados, el mismo ha permitido un remozamiento del sindicalismo. Fue lamentable el predominio de la polarización gobierno-oposición que se impuso sobre la del sindicalismo tradicional y las nuevas fuerzas emergentes en el movimiento.

El empecinamiento gubernamental en cuestionar los resultados electorales, más bien les ha perjudicado, ya que, al no incorporarse al Comité Ejecutivo, han dejado el campo libre para la fracción más vinculada a Acción Democrática,

23. Jesús Urbieta, coordinador de la Junta de Conducción Sindical, destaca que las federaciones regionales de los estados de Aragua, Apure, Cojedes y Guarico están en manos de mujeres. Y afirma que la edad promedio de los electos en sindicatos y federaciones es de 35-40 años (Ferrero, 2002). 
la oposición más contumaz en el espectro político ${ }^{24}$. Tanto la CTV como su fuerza política mayoritaria, en un breve plazo han venido recuperando espacios perdidos. El gobierno, indirectamente, ha contribuido a la recuperación de un opositor con capacidad de movilización y poder real, como es el movimiento sindical.

\section{La oposición conquista la calle}

Los primeros tres años de ejercicio gubernamental han empezado a mostrar signos de desgaste, y por tanto de fortalecimiento de opciones opositoras, aunque sigue observándose la preferencia de los sectores populares por el gobierno chavista.

En los primeros años del gobierno, los actores empresariales y sindicales tradicionales le hacen oposición, pero sin que ésta melle e influya mayormente en el comportamiento gubernamental. Una dosis de autoritarismo y un nivel de diálogo social casi inexistente evidencian que el actor estatal reitera su propósito de ignorar a los actores que considera comprometidos con la vieja política, aunque cada uno se haya legitimado en procesos electorales realizados en el transcurso del 2001.

A la altura del tercer año de gobierno se manifiestan, efectivamente, acciones que lo desafían exitosamente y empiezan a brindar los primeros signos de fortalecimiento de la oposición política. Es llamativo observar que se ha constituido una constelación de fuerzas políticas y organizaciones de la sociedad civil que han atendido convocatorias de protesta con participación masiva. La primera de estas convocatorias es el paro convocado por la organización de la cúpula empresarial, Fedecamaras, a la cual se adhirieron diversas organizaciones sociales, políticas y económicas, entre ellas la CTV, el pasado 10 de diciembre de 2001. Fue una iniciativa exitosa que paralizó en un 90\% las actividades económicas. Los empresarios encontraron eco entre sus afiliados y, en general, la sociedad consideró justificado el paro, por el hecho de que el gobierno, haciendo uso de poderes extraordinarios recibidos de la Asamblea Nacional, legisló sobre 49 distintos temas sin las debidas consultas como lo establece la propia constitución, lesionando derechos de participación, propiedad, justicia, libertad, derechos humanos y pluralismo político. Las leyes más controversiales fueron la de Tierras, de Pesca, de Hidrocarburos y de Turismo. Esta razón de la convocatoria al paro se vinculó con el malestar que se venía exteriorizando desde diversas e importantes instituciones de la sociedad civil, con las políticas gubernamentales que respaldaron el paro (López, 2002: 9). De

24. De incorporarse, sumarían tres miembros del Comité Ejecutivo. Dos procedentes de la plancha que encabezó Aristóbulo Isturiz, y la tercera la dirigente Rosa Sequera, que participó en plancha aparte. Por otro lado, está la plancha que encabezó Carlos Navarro -Alianza Sindical Independiente_-, que obtuvo un miembro en el Comité Ejecutivo, aún no siendo de posición oficialista, sí es opositor al liderazgo adeco de la confederación. 
este momento en adelante, la oposición promueve varias acciones de calle dirigidas a protestar por las políticas gubernamentales. El gobierno interpreta estas acciones como parte de una conspiración para derrocarlo, incluso critica la unidad entre empresarios y sindicatos; pero desde el movimiento sindical se interpreta como el despertar y la unidad de acción de diversos sectores que coinciden en la oposición al gobierno. Es un hecho circunstancial acelerado por el autoritarismo gubernamental (Ramos, 2002: 5). Del paquete de leyes aprobadas por el Ejecutivo sin las debidas consultas, importa directamente al movimiento sindical la relativa a la función pública, la que desmejoraba conquistas contenidas en la ley de carrera administrativa. Sin embargo, el gobierno dio un paso atrás para corregir los señalamientos sindicales, restituyendo derechos puestos en peligro.

\section{Tensiones máximas}

El fortalecimiento de la oposición, el desgaste gubernamental, la continuada recesión en la economía venezolana, la pugnacidad del discurso político, el ambiente de agresión abierto entre las distintas fuerzas y organizaciones que participan en el escenario político y social, han llevado a un ambiente de confrontación y movilizaciones que tuvieron su máxima expresión en los acontecimientos de movilización y violencia los días 11 al 14 de abril de 2002.

A lo largo de los últimos años, el clima de tensión política fue exacerbándose. En la medida que la oposición no tuvo capacidad para tomar la calle, ésta se manifestaba a través de los medios de comunicación, que se constituyeron en una amplia fuerza de criticismo del gobierno. Pero, después del paro del 10 de diciembre de 2001 y la multitudinaria marcha del 23 de enero de 2002, la oposición tomó la calle, y los adherentes al gobierno, que venían movilizándose a sus anchas desde hacia tres años, se empezaron a confrontar con las marchas de la oposición.

La oposición, en los primeros meses del 2002, empezó igualmente a formular propuestas dirigidas a presionar al gobierno, desde solicitar su rectificación, hasta la salida de Hugo Chávez del poder. Las propuestas planteadas eran:

1. Rectificación y respeto constitucional.

2. Referéndum: consultivo o revocatorio.

3. Enjuiciamiento presidencial: violación de la constitución, corrupción, condiciones mentales, entrega petrolera a $\mathrm{Cuba}^{25}$.

4. Reclamos laborales de reivindicaciones insatisfechas.

5. Reclamos ante el deterioro de la descentralización ${ }^{26}$ y la democratización (agresión a la libertad de expresión).

25. Para mediados del 2002, trece solicitudes de antejuicio contra el presidente habían sido consignadas ante el Tribunal Supremo de Justicia.

26. Desvío de fondos destinados a las regiones, especialmente a aquéllas cuyos gobernadores son de la oposición. 
6. Paros sectoriales y nacionales.

7. Salida de Chávez.

\section{El movimiento sindical y el 11 de abril del 2002}

El análisis de esta fecha y el papel del movimiento sindical es un tema complejo, por la pugnacidad que persiste en el ambiente político y laboral venezolano. Es destacable que, a pesar de haber transcurrido casi un año de los acontecimientos que dieron lugar a la sustitución del presidente Hugo Chávez, la asunción a la Presidencia por sólo 36 horas por parte de Pedro Carmona y el retorno nuevamente del presidente Hugo Chávez, acompañada esta turbulencia por pérdidas humanas, no existe una investigación confiable de estos sucesos $^{27}$. En el seno de la Asamblea Nacional no se ha aprobado la Comisión de la Verdad, con el debido piso legal que garantice su investigación. Se señala que la mayoría oficialista se ha opuesto a integrar esta comisión con personalidades independientes. Inmediatamente luego de los sucesos del $11 \mathrm{de}$ abril, se abrió un período de interpelaciones de civiles y militares comprometidos con los acontecimientos, y no fue posible que la Asamblea Nacional produjera un informe institucional, tan sólo se conoció de los informes de unos y de otros, del gobierno y de la oposición. La Asamblea Nacional le debe a la sociedad venezolana una mayor responsabilidad en el ejercicio de sus funciones.

La marcha del día 11 de abril es la concentración humana más multitudinaria que se conoce en la historia del país. Ese día la marcha fue convocada para llegar desde distintos lugares hasta Chuao, zona donde está ubicada Petróleos de Venezuela, para rendir solidaridad a los empleados petroleros en situación de huelga, pero posteriormente se decidió llevar la marcha a Miraflores, sede de la Presidencia, para protestar y pedir la renuncia del presidente. Frente al palacio del gobierno, en los últimos tres días se habían apostado miles de partidarios suyos. Ante el desvío de la marcha de la oposición, personeros del gobierno hicieron llamadas públicas a sus adherentes a instalarse frente al palacio presidencial para defender al gobierno. Esta confrontación dejó un trágico saldo de 19 personas asesinadas por francotiradores apostados con antelación al arribo de la marcha a este céntrico lugar de Caracas. En los dos días sucesivos, grupos afectos al gobierno toman las calles y se producen nuevas víctimas, especialmente de personas que defendían sus propiedades. Una organización defensora de los derechos humanos - Provea- calcula que se produjeron 40 muertes en los sucesos de violencia, particularmente en el oeste de Caracas, en los tres días sucesivos. Además, hubo saqueos de

27. Incluso ante la Justicia de España se ha presentado la demanda contra el presidente Hugo Chávez y veinticinco altos funcionarios gubernamentales, por crímenes de lesa humanidad, ya que entre las víctimas hubo uno de nacionalidad española. La Justicia española declinó por la investidura presidencial de H. Chávez. Sus acusadores llaman la atención que este juicio se reiniciaría al dejar la Presidencia. 
establecimientos comerciales. Los organismos empresariales que agrupan a los comerciantes indican mil establecimientos afectados y una pérdida de 80 mil empleos.

$\mathrm{El}$ antecedente inmediato de estos acontecimientos incluye paros parciales promovidos por los empleados petroleros, quienes protestaban por el nombramiento de una directiva de la empresa Petróleos de Venezuela, que violaba la llamada "meritocracia»" ${ }^{28}$. En la historia de esta industria se trata del primer paro promovido por los empleados. Los obreros petroleros apoyaron la huelga, pero con posturas ambiguas, no presentaron una posición coherente, algunos sectores sindicales apoyaron abiertamente el paro, y otros sólo declarativamente. En el seno de los obreros petroleros existía división, ya que la dirección de la mayor federación, Fedepetrol ${ }^{29}$, refleja en situación equilibrada la relación de fuerzas entre quienes apoyan al gobierno y quienes hacen oposición, además, las recientes elecciones sindicales del 2001, dejaron heridas aún no curadas en el movimiento sindical de este sector.

Finalmente, los empleados se fueron a una huelga cuando el presidente de la República despidió desde un programa televisivo, ante toda la nación, a los dirigentes de la protesta, todos ellos ocupantes de altos cargos gerenciales. La manera como ocurrió el despido de los directivos petroleros fue indignante y estimuló la protesta contra el gobierno. En este marco, la CTV convocó a un paro nacional por 24 horas, a pesar de una reacción de apoyo insuficiente por parte de la población, ya que actividades importantes se mantuvieron funcionando, como por ejemplo el transporte, los bancos, y el expendio de víveres y alimentos. Ese mismo día, la CTV extendió el paro a otras 24 horas, y finalmente lo declaró indefinido. Esta declaración, evidentemente, constituyó un desafío al gobierno, ya que estuvo acompañada de planteamientos de solicitud de la renuncia del presidente Hugo Chávez.

Se señala que directivos de la CTV venían participando en acciones conspirativas, particularmente la fracción vinculada con Acción Democrática, fuerza mayoritaria en la confederación. El 11 de abril, el comandante de mayor jerarquía de las Fuerzas Armadas, Lucas Rincón, anuncia, en la cadena nacional, la renuncia del presidente Hugo Chávez, y luego se informa, igualmente desde fuentes militares, que Pedro Carmona, presidente de la organización representativa de los empresarios — Fedecámaras — asumiría la Presidencia de la República. En el momento de la toma de posesión de Pedro Carmona, la representación de la CTV no participó de este acto, que fue avalado por los partidos políticos opositores, la Iglesia católica, los medios de comunicación y, obviamente, las organizaciones empresariales. Además, la composición del gabinete no incluía dirigentes sindicales, tan sólo había un asesor sindical, León

28. Se trata de política de recursos humanos que toma en cuenta la antigüedad y las jerarquías alcanzadas, para ser promovido a cargos de mayor responsabilidad.

29. En el sector petrolero existen otras centrales sindicales, tal es el caso de Fetrahidrocarburos y Sintraip, pero Fedepetrol aglutina por sí sola a más de la mayoría absoluta de los trabajadores del sector. 
Arismendi ${ }^{30}$, quien públicamente destacó que no participó de ninguna reunión conspirativa, y al conocer el contenido de los decretos del breve gobierno de Carmona, no llegó a presentarse para la toma de posesión. Se interpreta que, dada la composición tan conservadora del gabinete de Pedro Carmona, se hacía necesario incorporar a una persona con vínculos con el movimiento sindical, y por ello incluyeron a León Arismendi.

\section{CTV: ¿actor político o actor laboral?}

El desenvolvimiento de la vida venezolana en los últimos tres años se caracteriza por su alta politización. A la política se han incorporado multitud de personas que habían confiado en los partidos como sus representantes políticos, por ello, en las marchas y actos públicos del gobierno y de la oposición, se nota una participación que había venido menguando. Desde todos los estratos sociales se había incrementado la participación política. Los partidos tradicionales - $\mathrm{AD}$ y $\mathrm{COPEI}$ - señalaban contar con abultados números de inscritos, pero nunca lograron convocar las multitudinarias marchas y actos públicos que se ha visto a lo largo del 2002. Ahora los convocantes agregan nuevas organizaciones que conforman, junto con los partidos tradicionales, el movimiento sindical y empresarial, la llamada Coordinadora Democrática.

El movimiento sindical, en los primeros dos años del gobierno de Hugo Chávez, tuvo un perfil bajo. Los amplios triunfos electorales del oficialismo lo justificaban. Pero las primeras confrontaciones entre el gobierno y el movimiento sindical, como fueron la huelga petrolera de septiembre de 2000 y el referéndum sindical de diciembre de este mismo año, resultaron en victorias para éste último. A lo largo del 2001, las tensiones entre el gobierno y el movimiento sindical se acrecentaron, exacerbadas por llevarse a cabo las elecciones sindicales, en donde el gobierno intervino abiertamente. Mientras tanto, ocurrían igualmente tensiones en las relaciones entre el gobierno y el movimiento empresarial, lo que coadyuvó a un estrecho acercamiento de los sindicatos y los empresarios. Con la convocatoria al paro empresarial que devino en paro general, ambos movimientos devinieron en actores políticos centrales de la oposición al gobierno.

El escenario internacional, por las agresiones a la libertad sindical, llevó a la CTV a realizar diligencias exitosas en este terreno, particularmente en la OIT. Estos hechos llevaron a la CTV a ser uno de los pocos actores tradicionales de la política venezolana con capacidad de desafiar al gobierno, dentro y fuera del país. Los dirigentes de las fuerzas mayoritarias en la CTV destacan que es ineludible la acción política en la presente coyuntura como condición previa para la acción laboral. El gobierno señala que la CTV emprende acciones conspirativas. La confederación cuenta a su favor no haber convalidado el gobierno de Pedro Carmona, incluso no participó en su gabinete.

30. Profesor universitario y abogado laboral, asesor de sindicatos y perteneciente al Movimiento 1 de Mayo, que tiene representación en la directiva de la CTV en la persona de Rodrigo Penso. 
La agenda laboral está subordinada a la agenda política. Sobre los grandes problemas de esta agenda, el movimiento sindical ha tenido poca incidencia. En el terreno laboral, la situación más dramática es el desempleo, por la pérdida de puestos de trabajo y la falta de inversiones. El desempleo abierto ronda el $17 \%$. La informalización, que ya era alta — más del $40 \%$ - antes del gobierno de Chávez, ha alcanzado niveles nunca conocidos - por encima del 50\%-, las encuestas de hogares indican que ésta excedió al sector formal, con las consecuentes repercusiones en precariedad, deterioro de condiciones de trabajo y de vida. Hay que destacar que la mayoría de estos sectores no están organizados sindicalmente y que han sido terreno fértil para la cooptación gubernamental. Diversas agencias públicas promueven políticas clientelares con estos sectores (Gutiérrez, 2002).

Igualmente, en la agenda laboral, dos temas relevantes como la seguridad social y los ingresos merecen un señalamiento. El estado de la seguridad social es deficiente, por un deterioro que lleva décadas. El gobierno encontró una reforma de la seguridad social aprobada que no compartió, por lo que la desechó, pero en sus cuatro años de administración no ha logrado sustituirla por otra alternativa, continuando crecientemente el deterioro del desbordado sistema existente. Con la nueva constitución bolivariana, el oficialismo introdujo compromisos estatales que tienen dificultades en instrumentar, por lo populista y la falta de recursos materiales.

Con relación a los ingresos de los trabajadores, ciertamente el gobierno ha querido sustraer el manejo de las políticas salariales de las organizaciones sindicales. Por ello, a pesar de las exigencias legales, ha evitado convocar a la comisión tripartita para tratar lo relativo a los salarios mínimos, asumiéndolo por decretos inconsultos. En general, los trabajadores han perdido poder adquisitivo. Los convenios colectivos se continúan negociando, aunque las negociaciones son accidentadas en el sector público, cuando las corrientes sindicales opositoras dominan el sindicato. En el sector privado, la precariedad de los índices económicos, la disminución de la producción y los cierres de empresas colocan en situación de desventaja la posición negociadora de los sindicatos.

\section{La relación con el empresariado}

Se ha señalado que parte del empresariado se inclinó por la candidatura de Hugo Chávez, como reacción al desencanto con las políticas económicas seguidas en el régimen precedente de R. Caldera. Aunque siendo el otro candidato un antiguo dirigente del sector empresarial — Salas Romer-, quien con la descentralización emprendió una exitosa carrera administrativa en la Gobernación del Estado de Carabobo, ello le permitió mantener una cuota importante del apoyo gremial de este sector.

Sin embargo, a poco de iniciarse el nuevo gobierno empezó el distanciamiento con el empresariado, y fue este movimiento organizado en Fedecamáras quien se lanzó en primer lugar a un llamado general de paralización de actividades, la ocurrida el pasado 10 de diciembre. Paro que arrastró al movimiento sin- 
dical y que radicalizó el papel de las organizaciones opositoras al gobierno, porque se constituyó en la primera acción de calle en donde el gobierno salió derrotado. Sus extraordinarios esfuerzos en convocar a empresarios, organizar asambleas y ejercer presiones, con el objeto de desarmar el paro y no permitir su ocurrencia, fueron infructuosos. Es oportuno destacar que la alta capacidad de compra que tiene el gobierno es un argumento muy convincente en las relaciones con el empresariado, el cual por supuesto fue invocado en el conjunto de presiones.

A pesar de que los precios del petróleo han estado a muy buen nivel desde que Hugo Chávez asumió la Presidencia, en 1999, incluso en el 2001 y 2002, han estado por encima del precio referencial con el cual se elaboró el presupuesto nacional, sin embargo, se ha producido un incremento notable de la deuda pública interna. El gobierno ha emitido papeles que la banca adquiere para ponerlos a disposición del público, pero el alto porcentaje de estos papeles en poder de la banca plantea riesgos que ya implican la evasión de la banca para continuar adquiriendo más papeles emitidos por el gobierno ${ }^{31}$. Las relaciones con el sector bancario, que en un principio fueron cordiales, gradualmente se han venido deteriorando. El presidente exhorta al público a utilizar la banca estatal para mantener sus depósitos, pero la poca confianza en su administración hace poco atractiva la invitación. El gobierno ha gastado dinero que no se ha traducido en las correspondientes obras o mejoramiento de la calidad de vida de la población.

Con el empresariado nacional, las relaciones han sido ásperas. El discurso presidencial es crítico sobre el funcionamiento empresarial. Las leyes aprobadas enturbian las relaciones con el empresariado. Se incluyen la ley de tierras, la ley de pesca, de turismo, de hidrocarburos, la recurrencia frecuente a decretos de estabilidad laboral ${ }^{32}$. Luego del paro del 10 de diciembre de 2001 y las posteriores actividades de protesta que culminaron con el vacío de poder y el golpe de estado del 11 de abril del 2002, las relaciones han empeorado. Inmediatamente después del retorno de Chávez al poder, se convocó un diálogo nacional, los empresarios pusieron como condición la incorporación del movimiento sindical cetevista y el gobierno no aceptó, como consecuencia, el diálogo nació con el vacío de estas ausencias fundamentales.

Hay dos sectores empresariales con los cuales el gobierno ha querido mantener una relación no pugnaz, se trata de las pequeñas y medianas industrias, con quienes se ha venido elaborando la legislación del sector. Sin embargo, no se han dejado de cerrar empresas de este sector, por la continuada recesión económica. La organización cúpula de los pequeños y medianos industriales —Fedeindustria — fue desafiada por sus propios afiliados, cuando su presi-

31. Según los casos, entre el 50\% y el 70\% de los depósitos en la banca comercial privada son papeles del Estado. Por otra parte, la brutal devaluación del bolívar, 100\% en menos de un año, implica una severa disminución en el valor de los papeles de deuda pública nominados en bolívares (A. Durán, El Nacional, 23-9-2002, p. D-2).

32. Todos los años, con motivo del incremento del salario mínimo, se emite decreto de inamovilidad, que luego es renovado. En el caso del 2002, se ha mantenido la inamovilidad laboral por decreto desde hace ya más de un año. 
dente asumió una postura ambigua ante la convocatoria al paro empresarial del 10 de diciembre del 2001, pero las cámaras afiliadas se pronunciaron ampliamente a favor de la acción conflictiva.

La relación con las transnacionales ha sido ambigua. Se han hecho esfuerzos en invitarlos a invertir en Venezuela o a mantenerlos en el país. El discurso antineoliberal y antiglobalizador invocado frecuentemente, carece de medidas que lesionen al capital internacional. El capital internacional experimenta las incertidumbres propias del capital internacional que observa la inseguridad jurídica reinante. Los comportamientos conspirativos, que llevaron a la crisis del 11 de abril, no parecen estar asociados directamente al capital transnacional. El gobierno mismo no ha hecho señalamientos en este sentido. Mayor visibilidad se observó en el capital internacional en el prolongado paro de diciembre de 2002 y enero de 2003. El sector de empresarios transnacionales organizados en la cámara venezolana-americana ha exigido, de manera públi$\mathrm{ca}$, garantías y seguridades para sus inversiones.

Sin embargo, es el sector empresarial venezolano, desnacionalizado al ser absorbido por corporaciones transnacionales, quien ha advertido altos riesgos para el sistema democrático con el proyecto revolucionario del gobierno de Hugo Chávez, y se la ha jugado directamente en la confrontación con el gobierno. La asunción de la presidencia por parte de Pedro Carmona el pasado 11 de abril, quien en aquel momento ejercía la presidencia de Fedecámaras, comprometió aún más al empresariado en la lucha contra el gobierno. Es natural entonces que las relaciones entre el gobierno y el empresariado nacional se mantengan en situación de tensión permanente.

\section{¿En dónde estamos?}

Las organizaciones gremiales sindicales y empresariales han venido actuando coordinadamente desde el paro empresarial del 10 de diciembre del 2001. Este fenómeno es llamativo e indica que ambos han advertido en el gobierno nacional su opositor común. Sus afiliados han empujado a los liderazgos a posiciones más radicales. Las posturas moderadas son vistas con recelos. Abiertamente se plantea salir de Hugo Chávez. Las frecuentes convocatorias a paros y marchas son financiadas para quienes en ellas participen. No hay descuentos salariales por el ausentismo que plantean las marchas y los paros. Por su parte, el gobierno también financia a los empleados públicos que participan en sus frecuentes marchas y actos públicos, y a quienes no lo son les brinda apoyo material, alimentación, bebida, transporte y dinero en efectivo. Resultado: el país marcha a media máquina. En algunos sectores está postrado, actúa por inercia. En tiempos de globalización y competitividad, no hay inversiones que actualicen el aparato productivo, que se hace más obsoleto y desactualizado. Los centros productivos se abaratan cada vez más y están expuestos a seguir siendo engullidos por el capital internacional.

El gobierno confronta, no ha tendido puentes. Sus llamadas al diálogo, luego de la crisis del 11 al 14 de abril, fueron tan mezquinos que no convocó 
a la CTV, y en solidaridad, Fedecámaras no aceptó participar. Algunos líderes de gremios sindicales y empresariales aceptaron la invitación, pero al poco tiempo reconocieron que no había un diálogo transparente ${ }^{33}$. El gobierno se abstiene de todo trato formal con la CTV, porque no quiere reconocerla, incluso el Tribunal Supremo de Justicia tuvo que intervenir para que el gobierno reconociera que era la representación legítima en la Conferencia de la OIT.

La alianza tácita entre el empresariado y la CTV viene siendo criticada en el interior del movimiento sindical; por supuesto, en aquellos sectores en donde el liderazgo es cercano o amigo del gobierno, tales como en parte de las bases de la industria petrolera, de la industria siderúrgica y del aluminio de Guayana, en la industria automotriz, en el sector eléctrico y lo poco que queda del sindicalismo textil.

Las investigaciones de los sucesos del 11 al 14 de abril están impregnadas de intereses que pugnan por deformar los hechos. La madurez del sistema político está a prueba, si no se tiene capacidad para investigar objetivamente estos dramáticos sucesos, ello significa una evidencia más del deterioro del sistema político y sus instituciones. Cotidianamente, en la sociedad se discute con preocupación sobre el deterioro, la pugnacidad, el temor a una mayor violencia, y las organizaciones sociales, y por supuesto las sindicales y las empresariales, están en el centro de atención, ante las demandas de sus afiliados. El trágico camino recorrido por países de la región que fueron a la violencia y los liderazgos no pudieron evitarla, luego han tenido que pagar un alto precio por esa incapacidad. Es el espejo en el cual hay que mirarse. La crisis continúa. Encontrarle salidas es una tarea histórica que aún no se vislumbra, pero la sociedad mantiene un alto nivel de criticidad y denuncia, no hay lugar para el conformismo, el olvido y el silencio.

\section{Bibliografía}

Alfonso GuZMÁn, Rafael (1967). Estudio Analitico de la Ley del Trabajo Venezolana. UCV, dos tomos.

BERGQUIST, Charles (1986). Labor in Latin America: comparative essays on Chile, Argentina, Venezuela and Colombia. Stanford University Press.

CONSEJO Nacional Electoral (2002). La renovación de la dirigencia sindical en cifras. Impreso y en CD.

DOMBOIS, Rainer; PRIES, Ludger (2000). Relaciones laborales entre mercado y Estado. Sendas de transformación en América Latina. Caracas: Nueva Sociedad.

Ferrero, Mary (ed.) (2002). Chávez y el movimiento sindical en Venezuela. Alfadil Ediciones. Contribuciones de A. Martín, J. Urbieta, C. Ortega, A. Ramos, F. Barrios, C. Iranzo, R. Capriles, A. Padilla y C.R. Hernández.

33. José L Betancourt, presidente de la Asociación de Ganaderos; Carlos Navarro, presidente de la Alianza Sindical Independiente; representantes de los medios de comunicación impresos y audiovisuales. 
Gómez CalCaÑo, Luis (1995) «Crisis de legitimidad e inestabilidad política en Venezuela». Revista Venezolana de Economía y Ciencias Sociales, n. ${ }^{\circ} 2-3$, abril-septiembre, p. 103-164. FACES-UCV.

GuTIÉRREZ, Thais (2002). «La política social en situaciones de crisis generalizada e incertidumbre en Venezuela». Revista Venezolana de Gerencia, año 7, n. ${ }^{\circ} 18$. Maracaibo: Universidad del Zulia, p. 220-236.

ITURRASPE, Francisco (2000). «Democracia y conflicto. Deslegitimación del sistema político venezolano (1958-1998). La ilegalización de la huelga como índice de subdesarrollo político». Gaceta Laboral, vol. 6, n. ${ }^{\circ} 3$, p. 347-380.

Kelly, Phil (2002). «Democracy in Latín America. Update of the Fitzgibbon Survey». Lasa Forum, vol. XXXIII, n. ${ }^{o} 1$, primavera, p. 10-13. LASA.

LIVESLEY, Geraldine (1999). Democracy in Latin america: Mobilization, power and the search for new politics. Manchester, England: Manchester University Press, p. 232.

LÓPEZ, Margarita (2002). «Venezuela. El paro cívico del 10 de diciembre». Nueva Sociedad, n. ${ }^{\circ}$ 177, enero-febrero, p. 8-12.

LUCENA, Héctor (1999). «El enfoque de las relaciones industriales y los estudios laborales». En GARZA, Enrique de la (comp.). Los retos teóricos de los estudios del trabajo hacia el siglo XXI, p. 141-156. CLACSO, UAA y ASDI.

LUCENA, H.; HERNÁNDEZ, O. (1985). «Condicionantes políticos y económicos de la negociación colectiva en Venezuela». Revista Internacional del Trabajo, vol. 104, n. ${ }^{\circ}$ 2, abril-junio, p. 247-262. Ginebra: OIT.

LuCENA, H.; HernándeZ, O.; Goizueta, N. (1985), «Papel del sindicalismo venezolano ante la crisis económica». Revista Relaciones de Trabajo, n. ${ }^{\circ}$ 6, septiembre. Valencia: ART, p. 123-144.

MAINGON, Thais (1995). «Las elecciones de 1993: ¿cambios o profundizaciòn de las tendencias electorales». Revista Venezolana de Economía y Ciencias Sociales, n. ${ }^{\circ} 2-3$, abril-septiembre. FACES-UCV, p. 188-204.

MCCoY, Jennifer (1988). «Las consecuencias de la política de ajustes en las relaciones de trabajo en Venezuela». Revista Relaciones de Trabajo, n. ${ }^{\circ}$ 10-11. Valencia: ART, p. 204-226.

OXHORN, Philip (2001). «From human rights to citizenship rights? Recent trends in the study of Latin American Social Movement». Latin American Research Review, vol. 36, n. ${ }^{\circ}$ 3, p. 163-182.

ROMERO, Juan Eduardo (2001). «El discurso político de Hugo Chávez, 1996-1999». Espacio Abierto, Cuaderno Venezolano de Sociología, vol. 10, n. ${ }^{\circ}$ 2, abril-junio. Universidad del Zulia, p. 229-245.

VALECILLOS, Héctor (1989). «Acumulación de capital y desigualdades distributivas en la economía venezolana». Caracas: Instituto de Altos Estudios Sindicales.

VALSALICE, Luigi (1979). «La guerrilla castrista en Venezuela y sus protagonistas, 19621969». Caracas: Centauro.

\section{Hemeroteca}

El Nacional. Varias fechas en los períodos analizados.

Ramos, Alfredo. Miembro del Comité Ejecutivo de la CTV, entrevista en El Carabobeño, 13-5-2002, p. C5.

LeÓn, Luis Vicente. Director de Datanalisis, entrevista en El Carabobeño, 30-9-2002, p. C-5. 